\title{
Cuestiones de inmunidad. El patrimonio en el escenario de la globalización electrónica
}

Jorge Espinosa Morales | estudiante de arquitectura

URL de la contribución <www.iaph.es/revistaph/index.php/revistaph/article/view/3869>

Tras el advenimiento de la globalización electrónica, se explicitan aspectos como la construcción de un tiempo inmediato, acelerado y simultáneo, cuya finalidad se sitúa en la creación de un mundo homogéneo y sincronizado, donde el espectáculo mediante el consumo y la imagen técnica articula el desarrollo de la habitabilidad. Lo social se produce en la democracia biopolítica, quedando definida en el ámbito de lo individual, que está sometido por el consumo específicamente, y en el ámbito de lo colectivo, a través de los grandes aparatos-instituciones (consumo y medios de comunicación) que establece el ámbito de lo común en los grandes colectores del espectáculo.

Dentro de una nueva territorialización del mundo, el patrimonio estaría situado como meta-aparato (fotografía, cine, arquitectura, museo, archivo), en la etapa final de una globalización terrestre y en la emergencia monstruosa de la globalización electrónica. En este contexto, ¿Cuál es el papel de lo patrimonial?

El patrimonio en el contexto actual pertenece a una funcionalidad de la cultura de la mercancía, estableciéndolo como objeto de consumo. Aunque desde una perspectiva de la habitabilidad, lo patrimonial es una "manifestación de retorno a lo real" (MARCHÁN FIZ, 2015: 35-46) debido a que tiene la capacidad de producir una articulación simbólica-asociativa-biológica, que permite generar identidades colectivas.

La relación pasado-presente de lo patrimonial en este contexto de aceleración provoca que no se desarrolle solo como una herencia que modifica nuestro presente, sino como su inclusión en el presente altera las relaciones que existían con anterioridad. El pasado y el presente se superponen constantemente, por lo tanto, no se puede entender lo patrimonial como estático (un

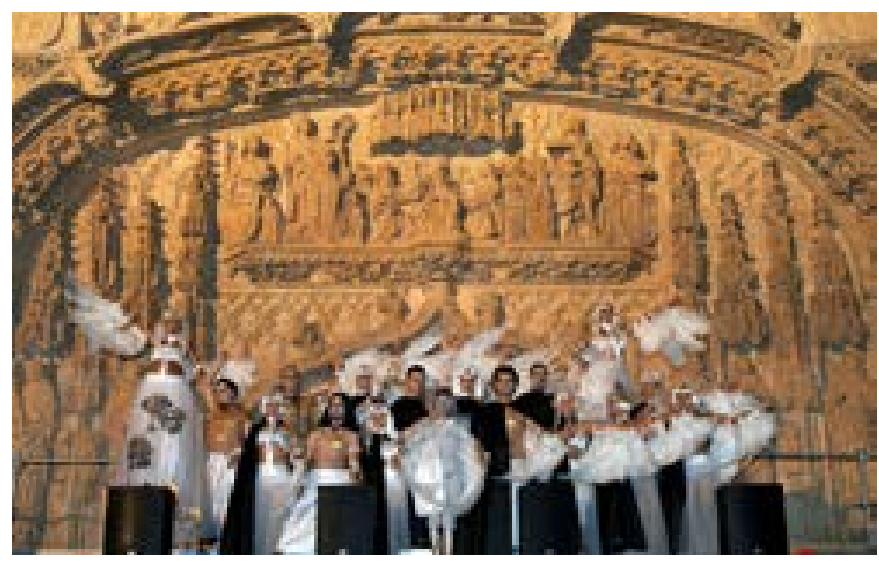

Espectáculo multimedia Las alas del ángel, de Xtrañas Producciones, con motivo de la restauración de la fachada de la iglesia de San Pedro (Valladolid) | foto Xtrañas Producciones

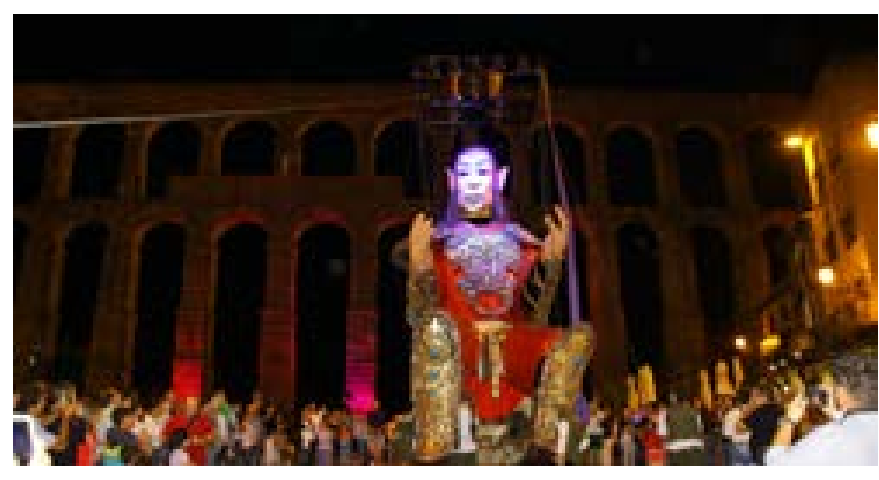

Salvador, la marioneta gigante de Carros de Foc, Street Theater, en Segovia | foto Carros de Foc

tiempo que sólo busca el consumo del objeto) sino que se encuentra en una mutación continuada.

"Desde el punto de vista inmunológico, habitar es una medida de defensa por la que se limita un ámbito de bienestar frente a invasores" (SLOTERDIJK, 2006). Desde esta reflexión, lo patrimonial debe plantearse como un sistema de inmunidad para las comunidades terribles, es 
decir, lo patrimonial sería un constructo donde se explicitarían experiencias alternativas al espectáculo, debido a dos componentes: una temporalidad alternativa, y una vinculación con la memoria.

Sobre el concepto de memoria, Montserrat Soto (2007) establece diferentes formas de memoria y alude a la memoria Bit/visual como la memoria de Internet, considerándola la red de redes y la red es el archivo de archivos. Lo patrimonial en su capacidad de configuración de una memoria y tiempo alternativo al de la globalización electrónica, debe vincularse a las posibilidades de relación y organización que permite lo virtual como red de archivos para explicitarlo en una habitabilidad inmunitaria, es decir, desarrollar procesos de negociación constantes que construyan una articulación de tiempos y memorias.

La capacidad de desarrollo de tiempos y memorias alternativos al tiempo sincrónico y acelerado hace relevante lo patrimonial; la complejidad viene de cómo se explicitan en la vida cotidiana y el proceso de adaptación que conlleva. Por lo tanto, como expresa Roland Recht: "No es un público multitudinario lo que el patrimonio necesita, sino un número regularmente creciente de individuos atentos, curiosos, motivados" (RECHT, 2014). Esa atención, curiosidad y motivación, debe ser construida por colectividades (incluyendo el papel institucional) que generen el patrimonio como un sistema de inmunidad dentro del escenario de la globalización electrónica.

\section{BIBLIOGRAFÍA}

- MARCHÁN FIZ, S. (2015) Patrimonio: resistir en la globalización. ASTRÁGALO, n. ${ }^{\circ}$ 20, julio 2015, pp. 35-46

- RECHT, R. (2014) Pensar el patrimonio: escenificación y ordenación del arte. Madrid: Abada. 2014 (Lecturas. Serie Historia del arte y de la arquitectura)

- SLOTERDIJK, P. (2009-2011) Esferas. 3. ${ }^{\text {a }}$ ed. Madrid: Siruela, 2009-2011, 3 v. (Biblioteca de ensayo. Serie mayor; $24,34,48)$

- soto, M. (2007) Archivo de archivos, 1998-2006. sl: Ajuntament de Lleida, 2007 